\title{
Combined PET/MR: A Technology Becomes Mature
}

\author{
Hans F. Wehrl ${ }^{1}$, Alexander W. Sauter ${ }^{1,2}$, Mathew R. Divine ${ }^{1}$, and Bernd J. Pichler ${ }^{1}$ \\ ${ }^{1}$ Werner Siemens Imaging Center, Department for Preclinical Imaging and Radiopharmacy, Eberhard Karls University Tuebingen, \\ Tuebingen, Germany; and ${ }^{2}$ Department of Diagnostic and Interventional Radiology, Eberhard Karls University Tuebingen, \\ Tuebingen, Germany
}

The combination of PET and MR imaging forms a powerful new imaging modality, PET/MR. The major advantages of concurrent PET/MR acquisitions range from patient comfort and increased throughput to multiparametric imaging and are evaluated and reviewed in this paper specifically with respect to their applications in research and diagnostics. Alongside the use of PET/MR in the field of preclinical research, this paper illuminates the impact of this new modality in the clinical field in such areas as neurology, oncology, and cardiology. Now that PET/MR technology has matured, attention is needed on standardizing education for nuclear and radiologic technologists and physicians specifically for this combined modality. Furthermore, the impact of this combined modality on health economy needs to be addressed in more detail to further propel its use.

Key Words: PET/MR; simultaneous imaging; multifunctional imaging; applications

J Nucl Med 2015; 56:165-168

DOI: 10.2967/jnumed.114.150318

More than a decade after the first introduction of prototype preclinical PET/MR systems (1), it is time to critically reflect on the state of PET/ MR technology and its current and future applications in both the preclinical and clinical settings.

Although the first ideas about combined PET/MR systems can be traced back to the late 1980s, with patent applications issued more than 20 y ago (2), the technologic evolution of PET/MR was much slower than that of PET/CT, which appeared on the horizon in the mid-1990s and was clinically available as soon as 2000 (3). The main reasons for the slow start of PET/MR into preclinical and clinical practice were mainly the technologic hurdles that needed to be overcome. Combining two imaging systems into a single PET/CT device is relatively straightforward, and the potential mutual interference between the two modalities is limited, unlike PET/MR, which requires a substantial engineering effort. However, the benefits of a combined PET/MR system are at least on a par with PET/CT, and its expected clinical and preclinical potential greatly exceeds the options for PET/CT, specifically in research applications (4).

\section{TECHNOLOGIC IMPLICATIONS}

The early years of PET/MR development focused on finding alternative approaches to photomultiplier tubes (PMTs) - the traditional PET detectors - which are sensitive to the magnetic field produced by MR systems. Field strengths near the strong main magnetic fields of MR scanners typically are $4.7-21 \mathrm{~T}$ preclinically and 1-3 $\mathrm{T}$ clinically. The primary approach to coping with the problem of strong magnetic fields was to place the PMTs outside the main magnetic field and link them by long optical fibers to the

For correspondence or reprints contact: Bernd J. Pichler, Werner Siemens Imaging Center, Department for Preclinical Imaging and Radiopharmacy, University of Tuebingen, Roentgenweg 13, D-72076 Tuebingen, Germany.

E-mail: bernd.pichler@med.uni-tuebingen.de

Published online Jan. 15, 2015.

COPYRIGHT (c) 2015 by the Society of Nuclear Medicine and Molecular Imaging, Inc. scintillation crystals (5). Most of these concepts focused on altering solely the PET detection system. However, modifications to the MR system in the form of dedicated split magnets $(\sigma)$ and systems that switched off the MR field during PET acquisition (7) have been presented. Unfortunately, these designs have to cope with some tradeoffs, either on the PET side, where the scintillation light is diminished by the use of long optical fibers, or on the MR side, where the MR performance is degraded by design compromises. The technical breakthrough for combined PET/MR came with the advent of semiconductorbased light detectors, which originated in particle physics and were insensitive to high magnetic fields $(8)$. These detectors replace the classic PMTs in PET and either exploit the avalanche photo effect in the form of avalanche photodiodes (APDs) (8) or more recently operate in the high-gain regime as Geigermode APDs, sometimes referred to as silicon PMTs or solid-state PMTs. Both APDs and Geiger-mode APDs perform well in comparison to PMTs, present a strong reduction in size compared with PMTs, and are not affected by even strong magnetic fields (9).

\section{THE QUEST FOR SIMULTANEITY}

Compared with PET/CT, in which the acquisition of PET and CT data is consecutive, most PET/MR system designs strive for concurrent collection of PET and MR data. There are many implications for simultaneous image acquisition. In contrast to PET/CT, in which the PET component usually requires substantially more time to accumulate image information than does the CT component, the time scales of PET and MR image generation are similar. The simultaneous operation allows for complex imaging workflows and multiple MR sequence acquisitions with different contrasts during the PET acquisition. Preclinical and clinical experience gathered over the last few years has shown that the time-saving advantages of simultaneous PET/MR acquisitions are substantial. For a standard small-animal PET/MR experiment, in which a static 10-min PET scan is combined with a highresolution anatomic MR image, both the time an animal spends under anesthesia and the total study time are reduced by roughly $50 \%$ compared with stand-alone data collection. A further advantage is the exchange of concurrent image data between the modalities: motion correction of the PET image based on MR navigator scans, multiple PET attenuation corrections during different breathing and heart phases, and MR-based PET reconstruction and partial-volume correction are just a few examples that unveil the full potential of simultaneous PET/MR.

Although the picture seems fairly one-sided for simultaneous imaging, there are some points in favor of sequential PET/MR acquisitions. First, the technologic challenges of a sequential PET/MR system are minor compared with those of a simultaneous imaging device. Second, in routine protocols, many tracers such as ${ }^{18} \mathrm{~F}$-FDG require an uptake time during which MR data can be acquired. Also, for many tracers the pharmacokinetic time scales have not exactly matched the time scales of the MR examinations (10). Third, two stand-alone modalities allow for the PET and MR scanners to be used separately on occasion, possibly reducing the initial investment and operation costs.

\section{THE STATE OF INSTRUMENTATION}

The technologic evolution that triggered the PET/MR revolution has spurred the development of varying PET/MR scanner concepts. Today, 
a clear tendency toward fully integrated PET/MR solutions based on semiconductor-based PET detectors is being seen preclinically and clinically.

In the preclinical field, commercial sequential PET/MR devices are available. They combine a 1-T permanent magnet-based small-animal MR system with a high-resolution PET system based on cerium-doped lutetium yttrium orthosilicate and position-sensitive PMT sensors (11). Such a system clearly shows that PET/MR is on the verge of taking over the coveted place once held by PET/CT systems in the preclinical field by joining highsensitivity molecular information provided by PET with the high resolution and superb soft-tissue contrast of MR imaging.

Simultaneous small-animal PET/MR systems concentrate on the use of APDs or silicon PMTs as detector technology. Our group has now built the second generation of small-animal PET/MR scanners (12), based on experience gained from our first-generation scanner (13). The current system is still maintained as a PET insert that can be installed inside the MR system or removed, allowing for stand-alone MR operation. However, it is likely that future animal PET/MR designs may be more tightly integrated into the MR environment with specially modified gradient system coils, as well as radiofrequency coils that are integrated into the PET ring.

The clinical PET/MR systems have been influenced by preclinical developments. Sequential PET/MR systems are in use and have, for example, the PET and MR installed in the same room but with a distance of approximately $4 \mathrm{~m}$ between the respective field-of-view centers (14). These combinations share the advantages of joining molecular with MR information but suffer from the drawback of nonsimultaneity. On the flip side, isochronous clinical PET/MR imaging is becoming more mature now that the second-generation scanners are in use. With the first generation of human PET/MR systems, based on APDs as light detectors centered on an insert design with a limited field of view that mainly allowed for brain imaging studies (15), much experience has been gained, which finally culminated in the second generation of simultaneous, clinical PET/MR systems. Whole body PET/MR systems feature PET detectors that are installed between the gradient and radiofrequency coil (16). The fully integrated, commercial, clinical whole-body PET/MR systems are based on APDs (16) or, more recently, even on Geiger-mode APDs, enabling timeof-flight PET scans (17). Measurements show that PET and MR can operate without a significant performance impact in this combination (16). Further developments such as silicon photomultipliers with integrated digitization directly in the detector modules have been presented (18).

It is now clear that sequential and simultaneous PET/MR systems are becoming more mainstream in both preclinical and clinical settings.

\section{APPLICATIONS}

The main benefits of PET/MR stem from the complementary nature of the two imaging systems. PET is one of the premier molecular imaging modalities and offers high sensitivity, in the picomolar range, as well as a wide spectrum of tracers for different applications. However, the metabolic information provided by PET often lacks anatomic landmarks, thus hampering image interpretation. These shortcomings of PET have been clearly addressed with PET/CT but with the drawback of the increased amount of ionizing radiation from CT and its inherent low soft-tissue contrast. MR offers not only high spatial resolution but excellent soft-tissue contrast that can often be achieved without the use of contrast agents. MR has the shortcoming of low sensitivity, with most applications being capable of reaching a sensitivity only in the millimolar range; this is where PET comes in as a welcome complement. Besides its anatomic imaging capabilities, MR imaging also offers a multitude of functional imaging properties. Examples of the major applications of PET/MR are summarized in Table 1. Further applications of preclinical and translational PET/MR imaging have been presented by Wehrl et al. (19).

Figure 1 shows the complementarities of PET/MR in the field of preclinical oncology. ${ }^{18} \mathrm{~F}$-FDG uptake in a tumor is compared with both T2-weighted and apparent diffusion coefficient maps generated from diffusion-weighted MR imaging. Simultaneous PET/MR is specifically advantageous in basic neuroscience investigations of connected-functional and morphologic-processes that are difficult to repeat because of, for example, pharmacologic stimulation.

\section{PET/MR IN THE CLINICAL SETTING}

Gradually, developments in small-animal imaging become part of clinical routine and provide physicians with powerful diagnostic imaging platforms. Now that small-animal and human systems share the same fundamental instrumentation, preclinical research results can be translated more easily into the clinic and vice versa.

One stereotyped but nevertheless important advantage of PET/MR over standard PET/CT scanners is the complete lack of radiation dosage during acquisition of the anatomic data.

Multifunctional and multiparametric imaging (Table 1) will illuminate the understanding of the pharmacokinetics of new PET tracers and permit cross calibration and validation of both systems. For these types of applications, the superior accuracy of image registration and fusion in both spatial and temporal domains is an enormous advantage. One must also keep in mind that simultaneous imaging enables an acquisition to capture the same physiologic parameters such as temperature, blood pressure, and heart rate.

It is expected that PET/MR will trigger new clinical applications. As an example, a patient with antisynthetase syndrome and fasciitis is shown in Figure 2. Only the combination with the MR sequences allows an interpretation of the ${ }^{18} \mathrm{~F}$-FDG uptake that is linked to inflammatory processes and not to muscle activation. However, in these times of tight budgets, multicenter studies are mandatory after completion of the basic research and comparative studies, to prove the diagnostic benefit. It needs to be emphasized that the pursued developments should be supported by improvements in governmental processes and clinical fellowships for hybrid imaging.

\section{COMPETING TECHNIQUES}

During the development of PET/MR, some of the perceived advantages of this new modality have been questioned (10). One major discussion centers on whether the benefits cannot be achieved by a simple fusion of images after separate acquisitions. This might be feasible for some basic clinical brain examinations, since the skull usually provides a relatively stable frame of reference for the brain tissue, allowing for relatively straightforward image fusion. However, our preclinical and clinical experience shows that image fusion is difficult in the abdominal area, where strong alterations by patient movement and positioning, as well as respiration and peristalsis, are observed. There, simultaneous PET/MR provides a clearly superior way to acquire data, compared with stand-alone techniques.

Hyperpolarized MR techniques have emerged recently and provide a multitude of insights into biochemical processes. Yet the quantity of injected hyperpolarized molecules exceeds physiologic levels so greatly that in some cases normal metabolism may be perturbed (20). The time scale of metabolic information obtained by hyperpolarized imaging is usually on the order of $1-2 \mathrm{~min}$. Therefore, this technique is complementary, rather than redundant, to PET/MR and may provide huge potential in the preclinical and clinical field on its own.

\section{CONCLUSION}

PET/MR has great potential in preclinical and clinical research as well as in diagnostic applications. It is likely that PET/MR will replace combined PET/CT in small-animal research, because of its inherent strengths such as soft-tissue contrast, multifunctional imaging capabilities, and the lack of ionizing radiation.

In the field of clinical research, PET/MR will no doubt make strides toward becoming the cornerstone of modern in vivo medical imaging applications. The advantage of measuring functional parameters without fluctuations in physiology with two modalities simultaneously provides an enormous potential to cross-calibrate new diagnostic methods ranging from perfusion to oxygenation measurements. PET/MR will especially become the modality of choice in the field of neuroscience when pharmacologic challenges are applied, demanding that multiple functional parameters be recorded simultaneously.

In clinical diagnostics, PET/MR will certainly not replace PET/CT as the major diagnostic tool in oncology. However, PET/MR will gradually make its appearance in disease detection and treatment control, starting at university hospitals and rapidly diffusing to larger radiologic and nuclear medicine practices.

Advances on the application side will undoubtedly trigger more widespread use of PET/MR, the combination of which has spurred advances in 
TABLE 1

Applications of PET/MR Imaging

\begin{tabular}{|c|c|c|c|c|c|c|}
\hline Field & Application & Description & Examples & PET tracer & MR method & Comments \\
\hline \multirow[t]{8}{*}{ Neurology } & $\begin{array}{l}\text { Cross-calibration; } \\
\text { multifunctional } \\
\text { imaging }\end{array}$ & $\begin{array}{l}\text { Monitor same metabolic } \\
\text { parameters with PET } \\
\text { and MR methods to } \\
\text { better quantify and } \\
\text { compare values } \\
\text { obtained by different } \\
\text { modalities; useful in } \\
\text { method development }\end{array}$ & Cerebral blood flow & ${ }^{15} \mathrm{O}-\mathrm{H}_{2} \mathrm{O}$ or ${ }^{15} \mathrm{O}$-butanol & ASL, contrast agents & $\begin{array}{l}\text { Comparison } \\
\text { measurements benefit } \\
\text { greatly from } \\
\text { simultaneous } \\
\text { acquisition, since } \\
\text { physiologic fluctuations } \\
\text { such as body } \\
\text { temperature and } \\
\text { respiration can be ruled } \\
\text { out as confounding } \\
\text { parameters }\end{array}$ \\
\hline & & & CBV & ${ }^{15} \mathrm{O}-\mathrm{CO}$ & $\begin{array}{l}\text { Contrast agents, VASO } \\
\text { imaging }\end{array}$ & \\
\hline & & & $\begin{array}{l}\text { Oxygenation, oxygen } \\
\text { extraction fraction, } \\
\text { and hypoxia }\end{array}$ & ${ }^{15} \mathrm{O}-\mathrm{O}_{2}$ & $\begin{array}{l}\text { BOLD and calibrated } \\
\text { BOLD techniques, } \\
{ }^{17} \text { O-MR }\end{array}$ & \\
\hline & $\begin{array}{l}\text { Monitor multiple stages } \\
\text { of metabolism; } \\
\text { multifunctional } \\
\text { imaging }\end{array}$ & $\begin{array}{l}\text { Use of functional imaging } \\
\text { capabilities of PET } \\
\text { and MR allows for } \\
\text { obtaining information } \\
\text { about multiple } \\
\text { metabolic steps in one } \\
\text { measurement }\end{array}$ & $\begin{array}{l}\text { Dopamine } \mathrm{D}_{2} \text {-receptor } \\
\text { binding and blood } \\
\text { flow during } \\
\text { pharmacologic } \\
\text { challenge }\end{array}$ & ${ }^{11} \mathrm{C}$-raclopride & ASL, CBV & $\begin{array}{l}\text { Use, for example, ASL } \\
\text { perfusion data for } \\
\text { advanced PET } \\
\text { modeling or CBV } \\
\text { measurements }\end{array}$ \\
\hline & & & $\begin{array}{l}\text { Foundations of MR BOLD } \\
\text { effect }\end{array}$ & $\begin{array}{l}{ }^{18} \mathrm{~F}-\mathrm{FDG},{ }^{15} \mathrm{O}-\mathrm{H}_{2} \mathrm{O} \\
{ }^{15} \mathrm{O}-\mathrm{CO}, \text { and }{ }^{15} \mathrm{O}-\mathrm{O}_{2}\end{array}$ & BOLD & $\begin{array}{l}\text { Use PET information to pin } \\
\text { down metabolic } \\
\text { components of BOLD } \\
\text { brain activation }\end{array}$ \\
\hline & Diseases & $\begin{array}{l}\text { Diagnosis of many } \\
\text { neurologic diseases } \\
\text { benefits from } \\
\text { additional information } \\
\text { gained by PET/MR }\end{array}$ & Stroke (tissue at risk) & ${ }^{15} \mathrm{O}-\mathrm{O}_{2}$ & ASL, VASO & $\begin{array}{l}\text { Use for basic research of } \\
\text { cerebral ischemia }\end{array}$ \\
\hline & & & Alzheimer disease & $\begin{array}{r}{ }^{18} \mathrm{~F}-\mathrm{FDG},{ }^{11} \mathrm{C}-\mathrm{PIB}, \\
{ }^{18} \mathrm{~F} \text {-florbetaben }\end{array}$ & $\begin{array}{l}\text { T1- and T2-weighted } \\
\text { imaging, volumetry, } \\
\text { MRS }\end{array}$ & $\begin{array}{l}\text { Combined information can } \\
\text { deliver clearer picture of } \\
\text { disease progression } \\
\text { and efficiency of } \\
\text { therapy }\end{array}$ \\
\hline & & & Neurooncology & ${ }^{11} \mathrm{C}$-methionine, ${ }^{18} \mathrm{~F}-\mathrm{FET}$ & $\begin{array}{l}\text { Contrast-enhanced MR } \\
\text { imaging, MRS }\end{array}$ & $\begin{array}{l}\text { Use for differentiation } \\
\text { between radiation } \\
\text { necrosis and } \\
\text { reoccurring tumor }\end{array}$ \\
\hline \multirow[t]{2}{*}{ Oncology } & Anatomic landmarks & $\begin{array}{l}\text { Use anatomic information } \\
\text { generated by MR for } \\
\text { better anatomic } \\
\text { orientation }\end{array}$ & $\begin{array}{l}\text { Tumor and metastasis } \\
\text { identification }\end{array}$ & $\begin{array}{l}{ }^{18} \mathrm{~F}-\mathrm{FDG},{ }^{18} \mathrm{~F}-\mathrm{FLT}, \\
\text { specific tracers such } \\
\text { as }{ }^{68} \mathrm{Ga} \text {-DOTATOC }\end{array}$ & $\begin{array}{l}\text { T1- and T2-weighted MR } \\
\text { sequences with } \\
\text { contrast agents }\end{array}$ & $\begin{array}{l}\text { Superior MR soft-tissue } \\
\text { contrast can often be } \\
\text { advantageous } \\
\text { compared with CT (Fig. 1) }\end{array}$ \\
\hline & $\begin{array}{l}\text { Tumor characterization } \\
\text { and staging }\end{array}$ & $\begin{array}{l}\text { Use anatomic and } \\
\text { functional information } \\
\text { provided by PET/MR } \\
\text { to gain better insight } \\
\text { into specific } \\
\text { biophysical and } \\
\text { metabolic changes }\end{array}$ & & $\begin{array}{l}{ }^{18} \mathrm{~F}-\mathrm{FDG},{ }^{18} \mathrm{~F}-\mathrm{FLT}, \\
\text { specific tracers such } \\
\text { as }{ }^{68} \mathrm{Ga}-\mathrm{DOTATOC}\end{array}$ & $\begin{array}{l}\text { ASL perfusion, } \\
\text { hyperpolarized } \\
\text { imaging, diffusion- } \\
\text { weighted MR imaging, } \\
\text { MRS, magnetization } \\
\text { transfer }\end{array}$ & $\begin{array}{l}\text { Complementarities of PET } \\
\text { and MR information are } \\
\text { used (Fig. 1) }\end{array}$ \\
\hline \multirow[t]{2}{*}{ Cardiology } & $\begin{array}{l}\text { Functional and anatomic } \\
\text { features of cardiac } \\
\text { activity }\end{array}$ & $\begin{array}{l}\text { Use metabolic } \\
\text { information provided } \\
\text { by PET for correlation } \\
\text { with anatomic and } \\
\text { functional features of } \\
\text { heart muscle provided } \\
\text { by MR imaging }\end{array}$ & $\begin{array}{l}\text { Infarct size } \\
\text { characterization }\end{array}$ & ${ }^{18} \mathrm{~F}-\mathrm{FDG}$ & $\begin{array}{l}\text { Contrast-enhanced MR } \\
\text { imaging, ejection } \\
\text { fraction, wall thickness }\end{array}$ & $\begin{array}{l}\text { Trigger information can be } \\
\text { used simultaneously for } \\
\text { PET and MR gating; } \\
\text { multiple PET } \\
\text { attenuation corrections } \\
\text { with MR in rest and } \\
\text { stress phases are } \\
\text { possible }\end{array}$ \\
\hline & & & $\begin{array}{l}\text { Cardiac metabolism in } \\
\text { general }\end{array}$ & $\begin{array}{c}{ }^{18} \mathrm{~F}-\mathrm{FDG},{ }^{18} \mathrm{~F}-\mathrm{FTHA}, \\
{ }^{13} \mathrm{~N} \text {-ammonia }\end{array}$ & $\begin{array}{l}\text { MR elastography/tagging } \\
\text { with sheer and stress } \\
\text { properties, MRS, MR } \\
\text { fiber tracking }\end{array}$ & \\
\hline
\end{tabular}

$\mathrm{ASL}=$ arterial spin labeling; $\mathrm{CBV}=$ cerebral blood volume; $\mathrm{VASO}=$ vascular space occupancy; $\mathrm{BOLD}=$ blood oxygenation level dependent; ${ }^{11} \mathrm{C}-\mathrm{PIB}=$ ${ }^{11} \mathrm{C}$-Pittsburgh compound B; MRS = MR spectroscopy; ${ }^{18} \mathrm{~F}-\mathrm{FET}=\mathrm{O}-\left(2-{ }^{18} \mathrm{~F}\right.$-fluoroethyl)-L-tyrosine; ${ }^{18} \mathrm{~F}-\mathrm{FLT}=3^{\prime}$-deoxy-3'-18 $\mathrm{F}$-fluorothymidine; ${ }^{18} \mathrm{~F}-\mathrm{FTHA}=$ ${ }^{18} \mathrm{~F}$-fluorothia-6-heptadecanoic acid. 


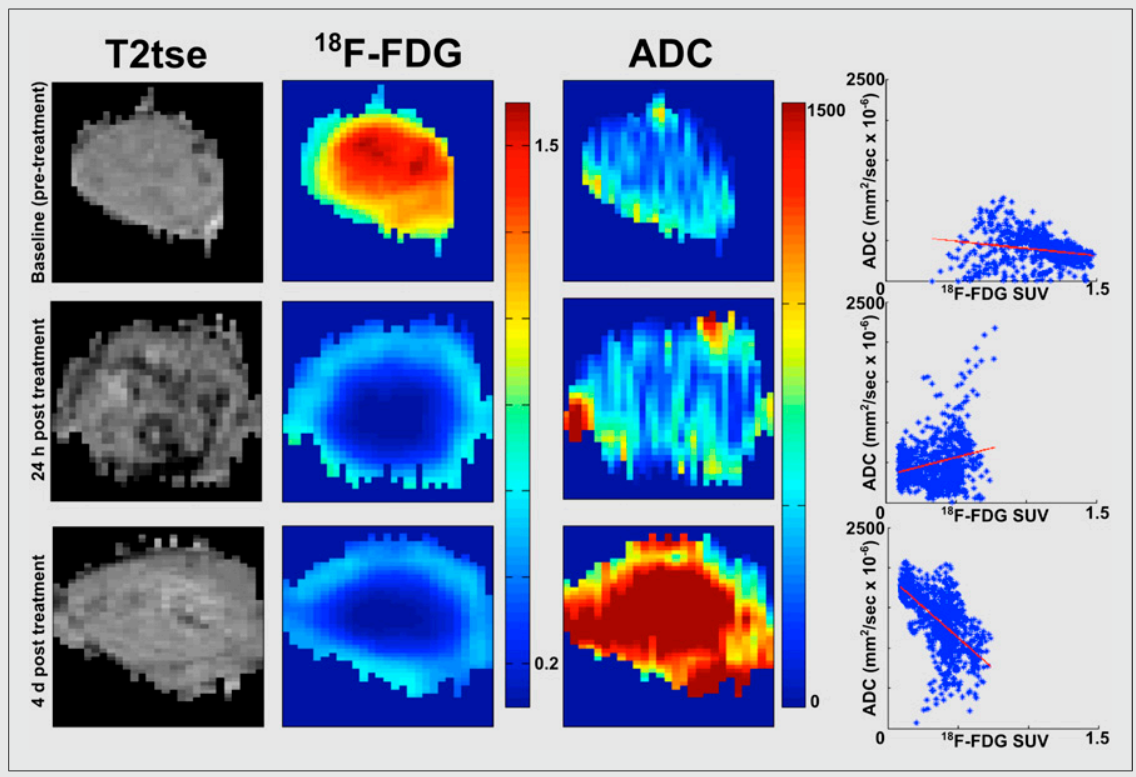

FIGURE 1. Longitudinal imaging study of treatment with non-small cell lung cancer xenograft tumor in nude mouse measured with T2-weighted turbo spin echo MR imaging (T2tse), apparent diffusion coefficient imaging (ADC), and ${ }^{18} \mathrm{~F}-\mathrm{FDG}$ PET is a nice example of the complementary nature of PET and MR imaging. Scatterplot on right with red best-fit line depicts how complementary information changes from baseline over course of therapy. Of particular interest is how ${ }^{18} \mathrm{~F}$-FDG signal decreases dramatically, revealing hypointense area in middle of tumor before apparent diffusion coefficient image shows significant changes. This dramatic decrease represents the time point of metabolic breakdown. SUV = standardized uptake value.

However, to exploit the full potential of this method, what needs to follow is the proper establishment of application protocols and training of users. With adequate nurturing, PET/MR will soon ripen to impact medical research and diagnostics at a whole new level.

\section{DISCLOSURE}

Research support was provided by the German Research Foundation (DFG PI 771-1 and DFG PI 771-3), the German Ministry for Education and Research (BMBF 01GQ1415 and BMBF FKZ 0316186E), the Swiss Werner Siemens Foundation, and the IZKF Junior Research Group Program at the University of Tuebingen (Functional and Metabolic Brain Imaging, fortüne 2209-0-0). No other potential conflict of interest relevant to this article was reported.

\section{REFERENCES}

1. Shao Y, Cherry SR, Farahani K, et al. Simultaneous PET and MR imaging. Phys Med Biol. 1997;42:1965-1970.

2. Hammer B, inventor. Intermagnetics General Corporation, assignee. NMR-PET scanner apparatus, No. 4939464. U.S. patent 4,939,464. July 3, 1990.

3. Beyer T, Townsend DW, Brun T, et al. A combined PET/CT scanner for clinical oncology. J Nucl Med. 2000;41:1369-1379.

4. Bailey DL, Barthel H, Beuthin-Baumann B, et al. Combined PET/MR: where are we now? Summary

PET instrumentation that are being integrated into PET/CT systems. Impressive has been not only the hardware implementation but also the speed of the development of other new, technically complicated applications such as MR-based PET image attenuation correction or motion correction.

PET/MR technology is now at a high readiness level of technologic maturity, with many systems already in preclinical and clinical operation.

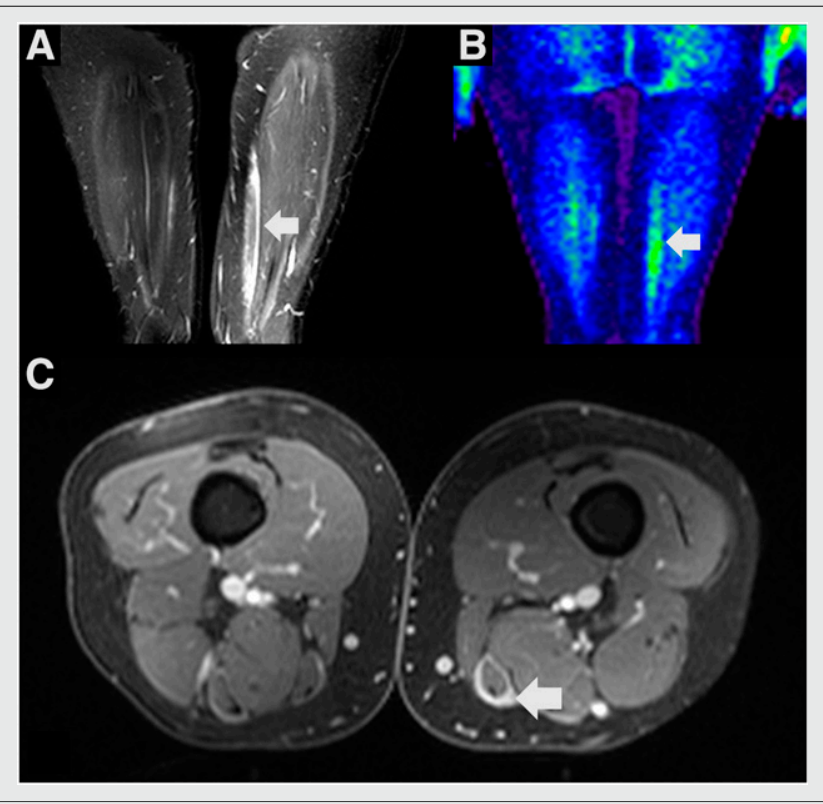

FIGURE 2. PET/MR imaging of patient with antisynthetase syndrome, a rare rheumatologic syndrome that is associated with interstitial lung disease, dermatomyositis, and polymyositis. In this patient, fasciitis of left gracilis muscle is shown as hyperintensity (arrow) on turbo inversion recovery magnitude MR sequence (A) that corresponds to hypermetabolic area (arrow) on ${ }^{18} \mathrm{~F}$-FDG PET (B). On T1-weighted fat-saturated postcontrast MR images (C), perimuscular enhancement (arrow) also documents underlying fasciitis. report of the second international workshop on PET/MR imaging April 8-12, 2013, Tubingen, Germany. Mol Imaging Biol. 2014;16:295-310.

5. Farahani K, Slates R, Shao Y, Silverman R, Cherry S. Contemporaneous positron emission tomography and MR imaging at 1.5 T. J Magn Reson Imaging. 1999;9:497-500.

6. Hawkes RC, Fryer TD, Siegel S, Ansorge RE, Carpenter TA. Preliminary evaluation of a combined microPET-MR system. Technol Cancer Res Treat. 2010;9:53-60.

7. Handler WB, Gilbert KM, Peng H, Chronik BA. Simulation of scattering and attenuation of $511 \mathrm{keV}$ photons in a combined PET/field-cycled MRI system. Phys Med Biol. 2006;51:2479-2491.

8. Pichler BJ, Lorenz E, Mirzoyan R, et al. Performance test of a LSO-APD PET module in a 9.4 Tesla magnet. In: IEEE Nuclear Science Symposium. Vol 2. Piscataway, NJ: IEEE; 1997:1237-1239.

9. Pichler BJ, Judenhofer MS, Catana C, et al. Performance test of an LSO-APD detector in a 7-T MRI scanner for simultaneous PET/MRI. J Nucl Med. 2006;47:639-647.

10. von Schulthess GK, Schlemmer HP. A look ahead: PET/MR versus PET/CT. Eur J Nucl Med Mol Imaging. 2009;36(suppl 1):S3-S9.

11. Nagy K, Toth M, Major P, et al. Performance evaluation of the small-animal nanoScan PET/MRI system. $J$ Nucl Med. 2013;54:1825-1832.

12. Wehrl HF, Hossain M, Lankes K, et al. Simultaneous PET-MRI reveals brain function in activated and resting state on metabolic, hemodynamic and multiple temporal scales. Nat Med. 2013;19:1184-1189.

13. Judenhofer MS, Wehrl HF, Newport DF, et al. Simultaneous PET-MRI: a new approach for functional and morphological imaging. Nat Med. 2008;14:459-465.

14. Zaidi H, Ojha N, Morich M, et al. Design and performance evaluation of a wholebody Ingenuity TF PET-MRI system. Phys Med Biol. 2011;56:3091-3106.

15. Schlemmer HP, Pichler BJ, Schmand M, et al. Simultaneous MR/PET imaging of the human brain: feasibility study. Radiology. 2008;248:1028-1035.

16. Delso G, Furst S, Jakoby B, et al. Performance measurements of the Siemens mMR integrated whole-body PET/MR scanner. J Nucl Med. 2011;52:1914-1922.

17. Delso G, Khalighi M, Hofbauer M, Porto M, Veit-Haibach P, von Schulthess G. Preliminary evaluation of image quality in a new clinical ToF-PET/MR scanner. EJNMMI Physics. 2014;1:1-2.

18. Weissler B, Gebhardt P, Lerche CW, et al. MR compatibility aspects of a silicon photomultiplier-based PET/RF insert with integrated digitisation. Phys Med Biol. 2014:59:5119-5139.

19. Wehrl HF, Wiehr S, Divine MR, et al. Preclinical and translational PET/MR imaging. J Nucl Med. 2014;55(suppl):11S-18S.

20. Gallagher FA, Bohndiek SE, Kettunen MI, Lewis DY, Soloviev D, Brindle KM. Hyperpolarized ${ }^{13} \mathrm{C}$ MRI and PET: in vivo tumor biochemistry. J Nucl Med. 2011;52:1333-1336. 